death. Little is known however, how parents make decisions around end of life care. Better understanding of the parental decision making process could lead to more effective care for families in similar circumstances as well as a better allocation of resources.

Method This qualitative study used semi-structured interviews with four bereaved parents and subsequent analysis by IPA to descibe the parental decision making process.

Results During curative treatment, the child's consultant was regarded as the main decision maker. At the end of life however, the responsibility for decision making lies solely with the parents (the children in this study were not informed of their impending death). Importantly, all participants describe disagreements with their partner, especially with regards to medical treatment decisions. In all families, the disputes were resolved by the mother acting as the main decision maker.

The most important factor in deciding in favour of further treatment was a belief that further treatment could be successful. The principal argument against further treatment was a concern regarding the quality of life for the child should the treatment succeed. The most important reason to take the child home to die was the parental perception that the child did not like the hospital. However, in deciding the place of death it was very important to ensure continued involvement of family and friends who had been supportive during the treatment. After the death of the child, engagement in altruistic and reciprocal activities was described as most helpful in bereavement.

Conclusion This retrospective pilot study allows some insight in the parental decision making process at the end of life of their child and calls for further study.

\section{G39 DELIVERING OPTIMUM CARE AT JOURNEY'S END: A COMPARISON OF BARRIERS TO END OF LIFE CARE PLANS BETWEEN A PAEDIATRIC ONCOLOGY SPECIALIST CENTRE IN THE USA AND A DISTRICT GENERAL HOSPITAL IN UK}

doi:10.1136/archdischild-2013-304107.051

1.2L Menzies, 'W Leith. 'Paediatrics, Whittington Hospital, London, UK; '2Institute of Child Health, University College London, London, UK

End of life care is a challenging but vital aspect for children with lifethreatening conditions, requiring parental discussion to plan appropriately. Parents express a need for open and honest information, delivered in a sensitive and timely manner. In adults, advanced care discussions (ACD) result in end of life care closer to patient preference, aligning care with patients' wishes. However there is often patient dissatisfaction regarding the timing and content of ACD.

A recent article in Pediatrics (Durall et al., 2012), identified barriers to conducting ACD for children in a paediatric oncology specialist centre in the USA. Following two challenging cases in our own unit, we assessed our colleagues' views at a district general hospital (DGH) in the UK, to see if similar barriers were pertinent despite contrasting hospital settings. 27 responses to a 23 -item survey, adapted from the above article, were compared with findings from the USA centre. Additionally, we explored differences in perceptions between consultants and junior doctors.

Similarities between the two hospitals were striking, with 5 of the 6 top barriers to ACD at the USA paediatric oncology centre being replicated at the DGH. Key issues in both settings included clinicians not knowing the right time to address issues, and clinician concern about removing hope. Of note, across the two centres, nurses identified lack of clinician time and lack of importance to clinician as barriers whereas doctors did not. For consultant paediatricians, specific barriers to ACD were differences between clinician/parent/patient understanding of prognosis and clinician uncertainty about prognosis. For junior doctors, specific concerns were not knowing the right time to address the issues or what to say.
This study demonstrates that similar barriers to ACD exist internationally. Junior and senior doctors identified particular concerns which could help enhance and target teaching at specific training levels. Findings from nurses suggest that doctors should reflect upon whether sufficient emphasis is given to ACDs and whether priorities should be revised.

\section{REFERENCE}

1. Durall A, Zurakowski D, Wolfe J. Barriers to conducting advanced care discussions for children with life-threatening conditions. Pediatrics, 2012(4)e975

\section{G40(P) WHAT DELAYS DISCHARGE IN CHILDREN WITH LIFE LIMITING CONDITIONS? A QUALITATIVE STUDY OF THE PERCEPTIONS OF PARENTS AND MEDICAL PROFESSIONALS}

doi:10.1136/archdischild-2013-304107.052

C Wensley. School of Medicine, University of Leeds, Leeds, UK

Background It is important that any family of a child with a life limiting condition (LLC) have the option of where they would like their child to receive care (ACT 2010, DOH 2008) and do not have unnecessary protracted periods of hospital admission.

Aims The aim of the project was to establish the perceptions of professionals and parents regarding perceived delay in discharge of children admitted acutely who had a LLC; also to look at ways to expedite discharge if appropriate.

Methods This study took place in a large tertiary teaching hospital. A qualitative approach was taken - one to one interviews with parents and focus groups with professionals. Inclusion criteria included parents of children with life limiting conditions admitted with acute illnesses.

Results The data was analysed using grounded theory. A model emerged of "separateness of expert knowledge" from the parents, community and hospital teams.

Conclusion This study, although limited in terms of participant numbers, explored the perceptions of parents and professionals around discharge in children with LLC admitted with acute conditions. The main finding was the "separateness of expert knowledge" between parents, community teams and hospital teams. All the groups included valued access to a professional who knew the patient well. Hospital staff and community teams felt that co-morbidities resulted in longer lengths of stay.

The reason for admission was not solely due to the acute diagnosis, but also lack of other adequate services for this group of children out of hours. There was no specific treatment identified that prevented discharge.

A multi-professional approach to the care of these children, with a robust system for discharge planning may enhance the service. A multi-professional out of hours telephone service for families of children with LLC may help reduce admissions.

\section{REFERENCES}

1. ACT's manifesto 2010: living matters for dying Children www.act.org.uk/manifesto accessed 15th June 2010

2. Department of Health 2008. Better Care Better Lives.

\section{G41(P) HANDLE WITH CARE: ADVANCE CARE PLANNING (ACP) IN PAEDIATRIC PATIENTS WITH PALLIATIVE CARE NEEDS: QUALITATIVE STUDY OF EXPERIENCES AND PERCEPTIONS OF PAEDIATRIC INTENSIVE CARE UNIT (PICU) MEDICAL AND NURSING STAFF}

doi:10.1136/archdischild-2013-304107.053

1,4S Mitchell, ' $J$ Dale. 'PICU, Birmingham Children's Hospital, Birmingham, UK; ${ }^{2}$ Health Sciences, University of Warwick, Coventry, UK; ${ }^{3}$ Oncology and Palliative Medicine, University of Cardiff, Cardiff, UK; ${ }^{4}$ Clinical Innovation and Research Centre, Royal College of General Practitioners, London, UK 